\title{
Percepções sobre o code-switching: espanhol e português na cidade de São Paulo
}

DOI: http://dx.doi.org/10.21165/el.v49i3.2460

\section{José André Teodoro-Torres ${ }^{1}$}

\section{Resumo}

Este trabalho investiga os possíveis significados sociais que o code-switching entre espanhol e português pode indiciar a partir da percepção sobre dois hispano-falantes. Para tanto, duas amostras de trechos de fala foram manipuladas para variar apenas na alternância (espanhol e português) e utilizadas para coletar dados qualitativos em entrevistas abertas $(N=10)$ e quantitativos em um experimento matched guise $(N=32)$. A literatura da área afirma que, até o momento, não se comprovou qualquer relação entre a produção de code-switching e o grau de escolaridade dos falantes (GARDNERCHLOROS, 2009), no entanto, a tendência popular é associar este mecanismo à preguiça e a níveis menores de inteligência. Os resultados obtidos nas análises estatísticas apontam que os falantes foram ouvidos como menos inteligentes quando utilizaram o code-switching. Além disso, dentre as características assinaladas para descrever os falantes, "preguiçoso" foi a terceira mais recorrente quando se ouviu o disfarce com a alternância, logo após "divertido" e "relaxado", adjetivos que corroboram a relação da produção deste mecanismo com situações de fala informal. Algumas das implicações deste trabalho são discutidas não somente com base na literatura sobre code-switching, mas também, em diálogo com trabalhos prévios sobre a percepção linguística.

Palavras-chave: code-switching; percepção; bilinguismo.

1 Universidade de São Paulo (USP), São Paulo, São Paulo, Brasil; jose.torres@usp.br; https://orcid.org/0000-0003-2467-9655 


\title{
Perceptions on code-switching: Spanish and Portuguese in São Paulo City
}

\begin{abstract}
This paper investigates the possible social meanings that code-switching between Spanish and Portuguese may indicate from the perception on two Spanish speakers. To this end, two speech samples were manipulated to vary only in alternation (Spanish and Portuguese) and used to collect qualitative data in open interviews ( $N=10)$ and quantitative data in a matched guise experiment $(\mathrm{N}=32)$. The area literature states that, so far, no relationship between the production of code-switching and the educational level of speakers has been proven (GARDNER-CHLOROS, 2009), however, the popular tendency is to associate this mechanism with laziness and lower levels of intelligence. The results obtained in the statistical analyses indicate that the speakers were heard as less intelligent when they used code-switching. In addition, among the characteristics marked to describe the speakers, "lazy" was the third most recurrent when the disguise with alternation was heard, right after "fun" and "relaxed", adjectives that corroborate the relationship between the production of this mechanism with informal speech situations. Some of the implications of this work are discussed, not only based on the code-switching literature, but also in dialogue with previous works on linguistic perception.
\end{abstract}

Keywords: code-switching; perception; bilingualism.

\section{Introdução}

Os trabalhos desenvolvidos na sociolinguística variacionista sempre buscaram entender como as línguas estão associadas a determinados espaços sociais e, portanto, se preocuparam não somente com o modo como as pessoas falam, mas também em entender como elas ouvem uma língua (CAMPBELL-KIBLER, 2010). Ainda que os estudos relacionados à percepção tenham uma longa história na Linguística, nos últimos quinze anos, houve um aumento significativo das pesquisas nesta área, especialmente no Brasil (MENDES, 2007; 2018; OUSHIRO, 2015; CANEVER, 2017).

A saber que muitos trabalhos em percepção buscaram documentar o estigma aplicado às minorias linguísticas (GILES; BILLINGS, 2004), este artigo examina como os falantes que produzem code-switching entre espanhol e português são percebidos por ouvintes hispano-falantes que vivem na cidade de São Paulo. A literatura sobre a produção de code-switching no Brasil não tem explorado questões de percepção de fala e pouco se sabe sobre o contexto de alternância entre português e espanhol em regiões não fronteiriças. Deste modo, o trabalho reportado aqui se apresenta possivelmente como um dos primeiros a explorar a percepção da alternância entre espanhol e português em São Paulo e a verificar se significados sociais, como inteligência e preguiça, observados em países hegemônicos se relacionam com o code-switching também no contexto brasileiro. 
Para o desenvolvimento do experimento, partiu-se, então, de estímulos manipulados de code-switching em trechos de fala espontânea de dois hispano-falantes e coletaram-se dados qualitativos por meio de entrevistas abertas e dados quantitativos por meio de um experimento do tipo matched guise aplicado on-line. Os resultados mostram que o codeswitching possui, sim, significado social, pois os disfarces ouvidos alteraram as percepções acerca dos falantes quando avaliados em termos de inteligência. Nota-se, portanto, que dentre a comunidade hispano-falante paulistana, a produção da alternância não detém prestígio, mas sim está associada a indivíduos ouvidos como menos inteligentes e a situações de fala mais relaxadas e/ou informais.

\section{Sobre o code-switching}

O code-switching, entendido como uma estratégia discursiva característica do falante bilíngue e definido como a alternância de palavras, expressões ou frases entre duas ou mais línguas (POPLACK, 1980), nas últimas décadas se desenhou como um dos pilares da literatura de línguas em contato e bilinguismo. Acredita-se, atualmente, que este mecanismo está presente em toda comunidade de indivíduos bilíngues, como famílias migrantes, membros de comunidades compostas por falantes de uma minoria linguística, ou indivíduos de países em que se adota uma língua franca diferente de sua língua materna (PORTO, 2006). Muitos capítulos e seções foram dedicados ao codeswitching nos principais volumes sobre bilinguismo e línguas em contato (LI WEI, 2000; THOMASON, 2001), assim como algumas coleções e edições especiais de periódicos se dedicaram à análise de diferentes aspectos desse mecanismo (HELLER, 1988; MILROY; MUYSKEN, 1995; AUER, 1998). No entanto, a produção bibliográfica sobre atitudes e avaliações acerca do code-switching ainda não é tão robusta quanto poderia ser.

Nas avaliações que falantes bilíngues espontaneamente fornecem sobre o codeswitching, o termo "preguiça" aparece como a justificativa mais recorrente quando se questiona o que está por trás da produção do code-switching (GARDNER-CHLOROS, 2009). Essa explicação é dada tanto por falantes que afirmam não alternar, quanto por aqueles que confessam produzir a alternância. Segundo Gardner-Chloros (2009), o codeswitching, aparentemente, é visto como uma saída fácil quando as pessoas não querem ter o trabalho de procurar as palavras de que precisam em uma única língua. Apesar da recorrência na associação entre a alternância e a ideia de um falante preguiçoso, e na contramão de crenças populares, a autora ainda afırma que até o momento não existem dados que comprovem uma relação direta entre o uso do code-switching e o grau de escolaridade das pessoas (GARDNER-CHLOROS, 2009). Em outras palavras, a produção de code-switching não é maior dentre pessoas menos escolarizadas, como se poderia acreditar. Por outro lado, o que, sim, foi comprovado é que os falantes alternam com maior frequência quando estão relaxados, em situações mais informais (GARDNERCHLOROS, 1991). 
Outro aspecto interessante levantado pela literatura é a não existência de uma relação categórica entre a produção de code-switching e gênero. Ainda que esta última seja considerada uma das categorias sociolinguísticas mais importantes historicamente e, apesar do conhecimento de que mulheres usam formas mais padronizadas do que os homens (LABOV, 2001), nos estudos sobre o code-switching, a relação entre esta categoria e a produção da alternância não é constante. Os dados de Poplack (1980), obtidos em um trabalho com porto-riquenhos em Nova lorque, apontam que as mulheres estariam mais propensas a produzir code-switching do que os homens. Enquanto isso, nos trabalhos desenvolvidos por Gardner-Chloros (2009) no Reino Unido, com um grupo de gregos cipriotas, não houve diferença significativa de qualquer espécie no que diz respeito a gênero. É possível, portanto, que a relação entre a produção de code-switching e gênero varie a depender do grupo sob análise e do comportamento das diferentes comunidades minoritárias e/ou migrantes.

Sobre este cenário, Dabène e Moore (1995) apontam algumas características comumente encontradas em contextos migratórios que provavelmente afetam o quadro linguístico. Em primeiro lugar, as circunstâncias da migração têm um impacto imediato na reestruturação das redes sociais dos diferentes grupos. Além disso, é possível que haja uma divisão entre o comportamento daqueles membros do grupo que desenvolvem laços estreitos com a comunidade anfitriã e aqueles cujas vidas giram em torno do lar (por exemplo, donas de casa ou idosos), que podem adquirir apenas habilidades mínimas na língua de acolhimento ou assumir um papel de guardiões da sua língua materna. Neste sentido, a relação entre produção de code-switching e gênero talvez esteja atrelada às características próprias de cada grupo migratório e aos papéis sociais que os homens e as mulheres desses grupos podem ocupar.

A partir dessa reflexão, busca-se, neste artigo, investigar se algumas relações estabelecidas pela literatura entre o code-switching e determinadas características sociais se comprovam entre membros da comunidade hispano-americana de São Paulo. Isto é, pergunta-se se os falantes são percebidos como menos inteligentes e/ou mais preguiçosos quando ouvidos a partir de um trecho de fala em que produzem codeswitching.

\section{Métodos}

Finalizada a observação dos significados sociais relacionados ao code-switching, o primeiro passo neste trabalho foi desenvolver entrevistas abertas com o objetivo de fazer um levantamento das atitudes dos participantes em direção aos áudios que ouviam e de quais termos utilizavam para caracterizar o falante e o code-switching presente nos excertos. Seguindo o modelo de Campbell-Kibler (2009), foram tocados trechos de fala contendo exemplos espontâneos de code-switching entre espanhol e português, produzidos por hispano-falantes que vivem na cidade de São Paulo, Enrique (Argentina) e 
Raúl (Colômbia). Durante esta primeira fase foram tocados dois áudios a 10 ouvintes das mesmas nacionalidades dos falantes e residentes na mesma cidade. Os participantes das entrevistas escutaram aos seguintes trechos:

\section{(1) Enrique}

Estoy con ganas de tomar una brejinha.

(2)

Raúl

Encontré cinco reales y Sergio me dijo: "cosas que acontecem".

Após a audição, foram feitas perguntas gerais sobre o áudio e o falante e também algumas perguntas diretas e específicas relacionadas aos significados sociais comentados acima. As perguntas eram: qual sua primeira impressão deste áudio?; o que você pensa desse modo de falar?; como você imagina esse falante?; o que você acha da alternância que ele faz para o português?; você diria que este falante está assimilado à cultura brasileira?; você diria que ele é menos inteligente por fazer a alternância?

As perguntas mais centrais desta etapa giravam em torno da relação entre o codeswitching e a inteligência e a hispanidade do falante. Enquanto a categoria de inteligência visava levantar comentários sobre a capacidade cognitiva do falante em separar as duas línguas, a de hispanidade tinha como objetivo descobrir se os participantes ouviam o falante como mais assimilado à cultura brasileira, e, portanto, menos hispânico, devido a sua produção de code-switching.

Para a segunda etapa, este trabalho utilizou o matched guise (estímulos pareados), uma técnica que visa provocar reações nos ouvintes para conjuntos linguísticos que diferem de maneiras específicas e controladas. A partir dos trechos de fala espontânea que compunham a etapa de entrevistas abertas, pediu-se que os falantes, Enrique e Raúl, repetissem alguns dos trechos coletados, mas dessa vez totalmente em língua espanhola, ou seja, sem a alternância. Como a relação entre a produção de code-switching e gênero não é categórica e pouco se sabe sobre as atitudes dos hispano-falantes residentes em São Paulo em direção ao code-switching, preferiu-se utilizar falantes do mesmo gênero para evitar que fatores ainda não conhecidos sobre essa população tivessem influência sobre as respostas. Assim, com os pares de trechos de fala (um com code-switching [CS] e outro totalmente em espanhol [E]), as funções "corta e cola" do software Praat (BOERSMA; WEENINK, 2007) permitiram que se retirasse o code-switching do primeiro exemplo e colasse neste espaço o seu correspondente em espanhol, produzido pelo mesmo falante em outra gravação. Dentre os estímulos produzidos pelos falantes, para este teste, foram escolhidos aqueles em que a alternância ocorria ao final da sentença, para diminuir possíveis diferenças na percepção dos ouvintes. 
Um dos benefícios da técnica matched guise é que ela permite que a única diferença entre os dois estímulos (CS e E) de um falante seja a variável de escolha do pesquisador, neste caso, a alternância. Portanto, a velocidade da fala, a entonação e os possíveis ruídos exteriores são os mesmos em ambos os trechos de fala de cada falante, que podem ser lidos abaixo:

(3) Enrique

CS. Estoy con ganas de tomar una brejinha.

E. Estoy con ganas de tomar una cervecita.

(4) Raúl

CS. Encontré cinco reales y Sergio me dijo: "cosas que acontecem"

E. Encontré cinco reales y Sergio me dijo: "cosas que pasan"

Estes estímulos (também conhecidos como disfarces) foram, então, organizados em dois conjuntos, conforme o quadro 1, e aplicados separadamente a diferentes ouvintes, que não haviam participado da etapa das entrevistas. Cada ouvinte teve acesso a somente um conjunto, isto é, uma pessoa pode ter ouvido o Enrique sob seu disfarce CS e o Raúl sob seu disfarce $E$, ou o inverso, mas nenhum participante ouviu o mesmo falante duas vezes ou dois trechos com o mesmo disfarce.

Quadro 1. Conjuntos de Estímulos

\begin{tabular}{|c|c|}
\hline $\mathbf{X}$ & $\mathbf{Y}$ \\
\hline Enrique CS & Enrique E \\
\hline Raúl E & Raúl CS \\
\hline
\end{tabular}

Fonte: Elaboração própria

Conjuntamente aos pares de estímulos foi aplicado um questionário (vide Anexo), criado com base em Campbell-Kibler (2009), desenvolvido no Google Forms e hospedado no Google Sites. Este formulário apresentava as categorias Formalidade, Inteligência, Amigabilidade, Confiabilidade, Hispanidade e Extroversão, elaboradas a partir da literatura e das reações explícitas dos participantes durante as entrevistas abertas e apresentadas em uma escala de 1 a 6 (Escala de Likert), variando de "pouco/nada" a "bastante/muito". Além disso, outros termos levantados pelos participantes das entrevistas para caracterizar os falantes foram distribuídos em uma lista de múltipla escolha, também presente no questionário, na qual os ouvintes deveriam selecionar adjetivos para descrever o falante que ouviram. O objetivo dessa segunda tarefa era levantar reações implícitas que os ouvintes pudessem ter em relação aos falantes a depender dos disfarces ouvidos. 
Por último, os ouvintes preencheram uma ficha, informando sexo, idade, nível de escolaridade, ocupação e tempo de residência em São Paulo. Assim, cada participante do experimento de matched guise ouviu a um conjunto com dois estímulos ( $X$ ou $Y$ ) e respondeu ao questionário duas vezes, uma para cada estímulo ouvido. Ao todo, 32 ouvintes completaram o teste (16 em cada conjunto), todos hispano-falantes e oriundos dos mesmos países que os falantes (Argentina e Colômbia).

As análises estatísticas dos dados obtidos pelo questionário foram realizadas com o auxílio do software R (R CORE TEAM, 2019), a partir do qual foram gerados gráficos boxplot e modelos de regressão linear de efeitos mistos. As análises desenvolvidas aqui possibilitam uma visualização de possíveis padrões encontrados em outros grupos de ouvintes da mesma população (hispano-falantes que vivem na cidade de São Paulo) respondendo a esses mesmos dois falantes.

\section{Resultados}

Para a análise estatística, as idades foram agrupadas em três faixas etárias: de 20 a 29 anos (13 ouvintes), 30 a 39 (12) e 40 a 55 (7). Com relação ao tempo de residência dos ouvintes em São Paulo, a variação é de 1 a 35 anos, com média em 4.75 e mediana em 3 anos. Já em termos de escolaridade, 6 participantes estudaram até o nível secundário (correspondente ao ensino médio no Brasil), enquanto os outros 26 têm nível superior. A metade dos participantes é de origem argentina (16) e a outra metade de origem colombiana (16). Por fim, participaram 15 homens e 17 mulheres.

Nas análises desenvolvidas no $R$ ( $R$ CORE TEAM, 2019), primeiramente criaram-se gráficos que ilustrassem a distribuição das respostas nas 6 escalas (Formalidade, Inteligência, Amigabilidade, Confiabilidade, Hispanidade e Extroversão) para verificar se a distribuição variava de acordo com o disfarce ouvido (CS e E). Os boxplots da figura 1 ilustram a distribuição para cada uma das escalas. Em todas elas, os boxplots mais escuros representam o CS, enquanto os mais claros representam o espanhol. A leitura dessas figuras indica pouca variação entre as notas atribuídas a cada falante a depender do disfarce ouvido, inclusive, em algumas escalas parece não haver disparidade nenhuma. Quando o Enrique foi avaliado em questões de Amigabilidade, seus boxplots para ambos os disfarces (CS e E) se assemelham bastante, o mesmo acontece com o Raul nas escalas de Confiabilidade e Extroversão. Portanto, o code-switching pareceu não influenciar como os falantes foram avaliados nessas categorias. O intervalo das notas nessas escalas difere mais de um falante para o outro do que entre os disfarces, o que talvez seja fruto de diferenças idiossincráticas da fala do Enrique e do Raul. 
Figura 1. Distribuições das respostas dos participantes nas escalas de Formalidade, Inteligência, Amigabilidade, Confiabilidade, Hispanidade e Extroversão para cada falante e de acordo com o disfarce ouvido (CS e E)
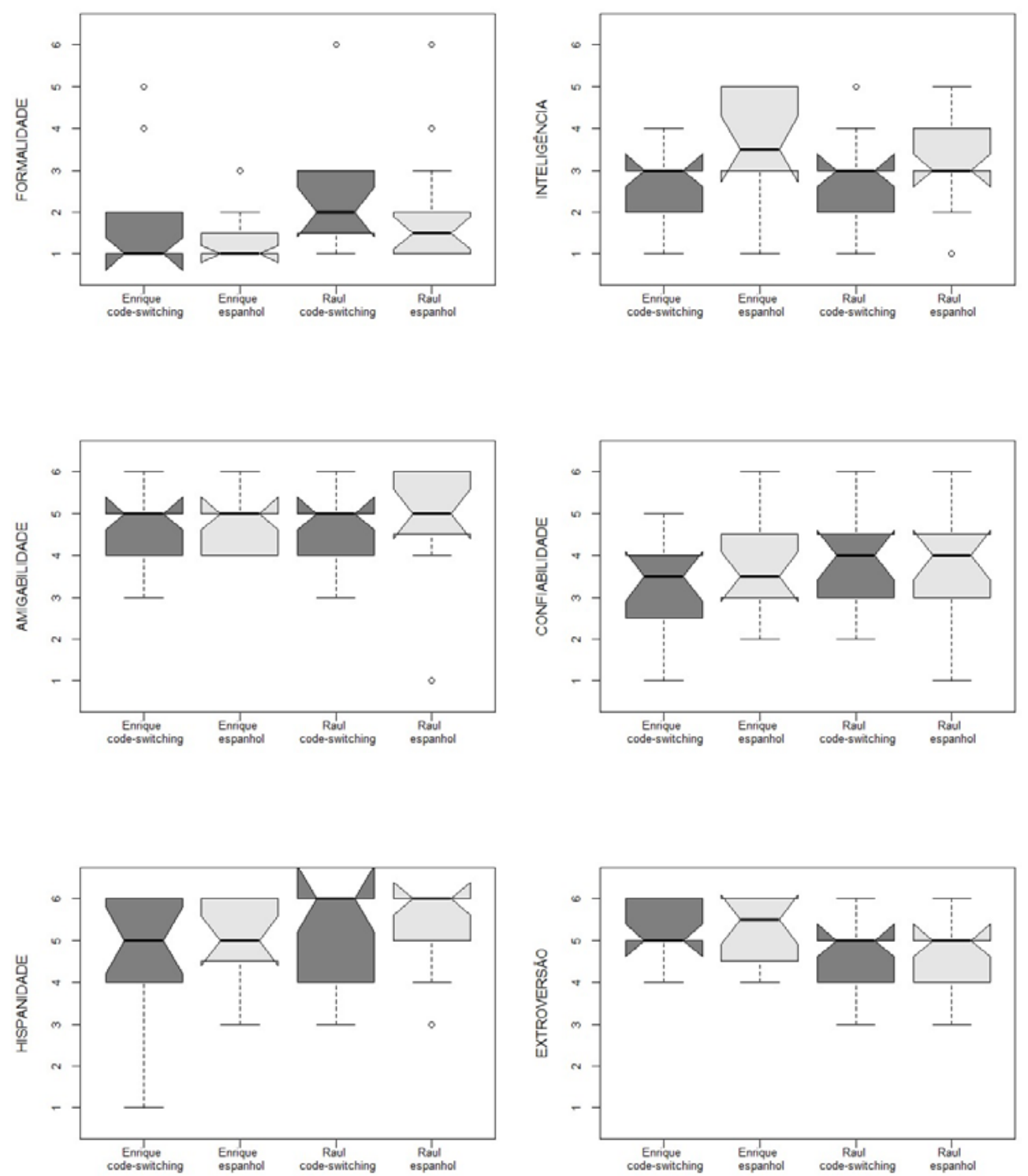

Fonte: Elaboração própria

Sabe-se, atualmente, que sotaque é um aspecto que tem influência na percepção e alguns estudos buscaram observar se existia correlação entre as avaliações positivas e negativas de alguma variável e sua associação a algum sotaque específico, em língua 
materna (CAMPBELL-KIBLER, 2009; PODESVA et al., 2015) e em segunda língua (LEIKIN et al., 2009). É possível, então, que as diferenças entre os sotaques argentino e colombiano atuaram sobre as avaliações das escalas de Amigabilidade, Confiabilidade e Extroversão, por serem, talvez, as que mais estão passivas de uma avaliação subjetiva ou de crenças ideais sobre o falar característico desses países. No entanto, sotaque não foi uma característica avaliada neste estudo, o que impede qualquer afirmação mais assertiva.

Quando se observa a escala de Formalidade, é notável que há uma diferença entre o tamanho dos boxplots do Raul a depender do disfarce ouvido. No entanto, essa diferença não se mostrou significativa em termos estatísticos no teste-t realizado. A escala de Hispanidade, por sua vez, apresenta boxplots similares independentemente dos disfarces utilizados por cada falante, o que também não caracteriza uma diferença significativa.

Apenas a escala de Inteligência mostra diferença nos valores dos boxplots a depender dos disfarces (CS e E). É possível obervar que os boxplots que representam o codeswitching (cinza escuro) estão mais abaixo que os que representam o espanhol (cinza claro). Essa diferença indica que as notas dadas aos falantes quando ouvidos utilizando o CS foram menores do que as que receberam quando sua gravação estava toda em espanhol. Contudo, o que interessa saber é se essa diferença representada nos boxplots para a escala de Inteligência é significativa em termos estatísticos. Para tanto, criouse um teste de Wilcoxon ${ }^{2}$ de duas amostras (inteligência e disfarce ouvido) para medir a diferença entre as médias das notas desses grupos e testar a hipótese nula de que essa diferença é igual a zero. No teste realizado, os valores do intervalo de confiança estimam que a diferença entre as notas na escala de Inteligência para os disfarces codeswitching e espanhol está entre - 1 e -4.02e- $05^{3}$, intervalo que não inclui zero. Além disso, o teste indica um valor-p inferior a 0.05 , de acordo com o resultado destacado na figura 2. Portanto, rejeita-se a hipótese nula de que não há diferença e verifica-se a hipótese alternativa, que indica que a diferença entre as médias das notas dadas a cada disfarce ouvido é, sim, significativa.

Figura 2. Resultado do teste de Wilcoxon sobre as amostras inteligência e disfarce ouvido

$$
\mathrm{W}=319.5, \mathrm{p}<0.05
$$

Fonte: Elaboração própria

Após a aplicação do teste de Wilcoxon e a verificação da hipótese alternativa, passou-se a um modelo de regressão linear (efeitos mistos) que verifica as interações entre duas

20 teste de Wilcoxon é um teste não paramétrico que compara a diferença entre as médias de dois conjuntos, cuja distribuição não é normal, e indica se esta diferença é igual ou não a zero (OUSHIRO, 2017).

3 A notação -4.02e-05 equivale a -0,0000402. 
ou mais variáveis previsoras. O teste estatístico já indicou diferença significativa entre os valores atribuídos à Inteligência a depender do disfarce (CS ou E), agora a tabela 2 apresenta valores que permitem comparar os resultados dados aos disfarces ouvidos com a variação das notas por falante. Além disso, este modelo admite a inclusão de um efeito aleatório, o que permite maior precisão nos resultados. Segundo Oushiro (2017), na estatística, uma variável é chamada de aleatória porque normalmente muda a cada amostra. Se este mesmo experimento fosse aplicado a outros ouvintes aleatórios (argentinos e colombianos), provavelmente haveria homens e mulheres na nova amostra, porém é pouco provável que os mesmos 32 ouvintes estivessem presentes no novo recorte. Considerando que "muito da variabilidade nos dados vem dos próprios indivíduos" (OUSHIRO, 2017, p. 174), se faz necessária sua inclusão como efeito aleatório para evitar enviesamentos no resultado final dos modelos estatísticos.

Tabela 1. Resultados do Modelo de Regressão para a escala Inteligência (efeitos mistos)

\begin{tabular}{l|c|c|c|c}
\hline & Estimativa & Erro padrão & valor t & valor p \\
\hline (Intercept) & 2.50 & 0.27 & 9.12 & $<0.001$ \\
\hline disfarce Espanhol & 1.00 & 0.38 & 2.58 & $0.01^{\star}$ \\
\hline falante Raúl & 0.25 & 0.38 & 0.64 & 0.52 \\
\hline disfarce Espanhol: falante Raúl & -0.50 & 0.59 & -0.83 & 0.41 \\
\hline
\end{tabular}

Total N: 64. Efeito aleatório: Ouvinte (32)

. $p>0.05 ;{ }^{\star} p<0.05 ;{ }^{\star \star} p<0.01 ; * \star * p<0.001$

Fonte: Elaboração própria

Na tabela 2, os valores da coluna Estimativa são interpretados em relação ao Intercept (ou nível de referência) que, para esse modelo de regressão, foi estabelecido como Enrique, na sua versão CS (os valores de referência são, por default na plataforma R, definidos pela ordem alfabética; neste sentido Enrique precede Raúl e CS precede E). Assim, a primeira linha da coluna Estimativa, 2.50, é o valor estimado pelo modelo, no quesito Inteligência, para Enrique, quando ouvido no disfarce CS. Na segunda linha dessa mesma coluna, o valor 1.00 deve ser somado à estimativa de Enrique/CS (presente na linha superior), para se obter a estimativa de Enrique sob seu disfarce E. Ou seja, 1.00 é a diferença entre as estimativas para os dois disfarces, na escala de Inteligência. O valor-p 0.01 , na última coluna, indica que seriam pouquíssimas as chances de obter esses mesmos resultados caso a hipótese nula fosse verdadeira (em outras palavras, caso não houvesse diferença entre Enrique/CS e Enrique/E). Deste modo, os valores apresentados reforçam que a diferença entre os disfarces é significativa.

Seguindo o mesmo raciocínio, soma-se o valor da terceira linha da coluna Estimativa para obter o valor da diferença entre falantes sob o disfarce referência (CS). Ou seja, o valor 
0.25 deve ser somado a 2.50 para se obter a estimativa de Raul na sua versão CS. Porém, o valor-p indicado para o falante Raul, 0.52, indica que a diferença entre falantes não é significativa. Isso confirma o que já se havia observado nos boxplots: a diferença entre os valores atribuídos à inteligência varia significativamente de acordo com o disfarce ouvido, mas não de acordo com o falante.

O próximo passo nas análises foi verificar se havia interação entre as notas dadas aos disfarces ouvidos na escala de Inteligência e as características demográficas dos ouvintes. Em outras palavras, buscou-se averiguar se o sexo (feminino e masculino), a escolaridade (secundário e superior), a faixa etária (1a.; 2a.; 3a.) e a origem dos ouvintes (Argentina e Colômbia) influenciaram as notas que eles deram a cada disfarce ouvido. Para tanto, criaram-se modelos que verificassem possíveis interações das variáveis demográficas quando comparadas uma a uma com os disfarces ouvidos. O valor-p acima de 0.05 em todos os modelos testados indica que as características demográficas dos ouvintes não tiveram influência sobre o modo como eles perceberam os falantes.

Após a verificação de que Inteligência foi a única escala que apresentou diferença significativa nas respostas a depender dos disfarces ouvidos, buscou-se observar, então, quais foram as características assinaladas pelos ouvintes quando ouviram os diferentes disfarces e como elas se relacionam, em caso afirmativo, com a escala de Inteligência. Durante a etapa de entrevistas abertas, foram reportados adjetivos para caracterizar os falantes e alguns destes termos estavam apresentados em uma lista não escalar no formulário de percepção. A tabela 2 apresenta o número de ocorrências das características assinaladas para cada disfarce ouvido.

Tabela 2. Número de ocorrências dos termos utilizados para caracterizar os falantes sob os disfarces CS e E

\begin{tabular}{c|c|c}
\hline & $\begin{array}{c}\text { N. de ocorrências } \\
\text { (disfarce CS) }\end{array}$ & $\begin{array}{c}\text { N. de ocorrências } \\
\text { (disfarce E) }\end{array}$ \\
\hline relajado & 22 & 28 \\
divertido & 18 & 21 \\
perezoso & 7 & 4 \\
ingenioso & 6 & 8 \\
inculto & 4 & 5 \\
habilidoso & 3 & 5 \\
hétero & 3 & 3 \\
trabajador & 3 & 6 \\
experto & 2 & 2 \\
nacionalista & 2 & 1
\end{tabular}




\begin{tabular}{c|c|c} 
gay & 1 & - \\
molesto & 1 & - \\
solitário & 1 & 1 \\
religioso & - & 1 \\
\hline TOTAL & 73 & 85 \\
\hline
\end{tabular}

Fonte: Elaboração própria

Apesar da lista de palavras estar localizada justo abaixo das escalas no formulário de percepção, a atenção que os ouvintes dão a cada uma das partes nem sempre é a mesma. Sobre isso, Mendes (2018, p. 74) afirma que "julgar como alguém soa através de uma escala (de 'pouco/nada' a 'bastante/muito') acaba sendo mais fácil e, de certo modo, mais objetivo do que qualificar a imagem que se construiu de alguém com adjetivos que podem parecer 'categóricos demais"'. Devido a isto, as respostas obtidas na lista de palavras não se relacionam tão claramente com o apresentado nas escalas anteriormente analisadas. Isto é, enquanto Inteligência foi a escala mais representativa, as características mais vezes assinaladas foram "divertido" e "relajado" (relaxado/tranquilo). Por outro lado, "inculto", uma característica que poderia ter correlação com a escala de Inteligência, não obteve muitos votos e, o número de ocorrência desta característica para classificar cada disfarce é quase equivalente.

A diferença entre o número de vezes que "relajado" e "divertido" apareceram nas respostas em relação às características que vêm em seguida ("perezoso" e "ingenioso") é mais do que o triplo para o primeiro, e mais que o dobro para o segundo em ambas as colunas. Isso indica que em alguns formulários essas foram as únicas características assinaladas. Tendo em vista o que Mendes (2018) afirmou anteriormente, é possível que os ouvintes não tenham se sentido confortáveis em qualificar os falantes com adjetivos que expressassem características negativas e, por isso, a preferência por aqueles que pareciam mais neutros frente aos estímulos informais, preparados para este experimento.

Embora não haja um número de ocorrências expressivo para a característica "perezoso" (preguiçoso), é interessante, porém, observar que quando os falantes foram ouvidos com a disfarce CS, esta é a terceira categoria mais assinalada. Sua alta colocação dentro do ranking da coluna CS pode ser prontamente relacionada com o que apontava GardnerChloros (2009) sobre a crença de que falantes que utilizam o code-switching são mais preguiçosos do que outros. Infelizmente, devido ao baixo número de ocorrências (7), é difícil relacionar essa característica de maneira significativa com alguma das escalas. 


\section{Discussão}

Do ponto de vista da escala de Inteligência, ambos os falantes (Enrique e Raúl) foram percebidos como homens que soam menos inteligentes quando produzem o CS e mais inteligentes quando não o produzem. Entretanto, essa diferença não encontra correspondência nas características assinaladas na lista de palavras. Considerando que o CS é uma variável que, segundo a literatura, ainda não carrega estereótipos de escolaridade ou classe (GARDNER-CHLOROS, 2009), o resultado obtido neste experimento parece se relacionar principalmente com o recorte da população participante. Em outras palavras, ainda que não haja grandes debates sobre a correlação entre o code-switching e a percepção de inteligência do falante, quando se trata da interação entre espanhol e português em São Paulo, os hispano-falantes parecem não endossar a alternância.

Acredita-se que o baixo número de ocorrências da característica "inculto" na tabela 3 se relaciona com um cuidado dos falantes em não se exporem de maneira negativa em um experimento conduzido por brasileiros em São Paulo. Seguindo essa lógica, talvez, esse também seja o motivo pelo qual os ouvintes utilizaram mais adjetivos, em números totais, para caracterizar o disfarce $\mathrm{E}$ do que o disfarce CS (tabela 3). Em um experimento como este, cabe indagar se a proximidade tipológica entre espanhol e português e o papel que o português ocupa como língua de prestígio no Brasil tiveram influência sobre as respostas dadas pelos ouvintes quando ouviram o disfarce CS. Em termos de percepção, trabalhos que precederam este comprovaram que tanto elementos internos, quanto externos ao experimento podem influenciar os resultados obtidos.

De todo modo, o experimento aqui realizado mostrou que o code-switching pode, sim, carregar significados sociais que são interpretados pelos ouvintes. Além disso, este trabalho contribui para a observação de um mecanismo linguístico e de uma população ainda pouco contemplados em termos de percepção sociolinguística. Trabalhar questões de code-switching em um espaço não canônico europeu, norte-americano ou fronteiriço (como a cidade de São Paulo) e com um par de línguas que não inclui o inglês ou o francês, como foi realizado aqui, é fundamental para a expansão das pesquisas relacionadas ao contato linguístico e aos contextos de bilinguismo.

\section{REFERÊNCIAS}

AUER, P. (ed.). Code-switching in Conversation: Language, Interaction and Identity. London: Routledge, 1998.

BOERSMA, P.; WEENINK, D. Praat: doing phonetics by computer. Disponível em http:// www.praat.org/. Acesso em: 11 jan. 2019. 
CAMPBELL-KIBLER, K. The nature of sociolinguistic perception. Language Variation and Change, Cambridge University Press, v. 21, p. 135-156, mar. 2009.

CAMPBELL-KIBLER, K. Sociolinguistics and perception. Language and Linguistics Compass, v. 4, n. 6, p. 377-389, jun. 2010. Disponível em https://onlinelibrary.wiley.com/ doi/10.1111/j.1749-818X.2010.00201.x. Acesso em: 11 jan. 2019.

CANEVER, F. Infinitivo flexionado em português brasileiro: frequência e percepções sociolinguísticas. 2017. Tese (Doutorado em Semiótica e Linguística Geral) - Faculdade de Filosofia, Letras e Ciências Humanas, Universidade de São Paulo, São Paulo, 2017.

DABÈNE, L.; MOORE, D. Bilingual speech of migrant people. In: MILROY, L.; MUYSKEN, P. (org.). One Speaker, Two Languages: cross-disciplinary perspectives on code-switching. Cambridge: Cambridge University Press, 1995. p. 17-44.

GARDNER-CHLOROS, P. Language Selection and Switching in Strasbourg. Oxford: Oxford University Press, 1991.

GARDNER-CHLOROS, P. Code-switching. Cambridge: Cambridge University Press, 2009.

GILES, H.; BILLINGS, A. C. Assessing language attitudes: speaker evaluation studies. In: DAVIES, A.; ELDER, C. The handbook of applied linguistics. Malden, MA: Blackwell, 2004. p. 187-209.

HELLER, M. (org.). Codeswitching: anthropological and sociolinguistic perspectives. Berlin: Mouton de Gruyter, 1988.

LABOV, W. Principles of linguistic change: social factors. Oxford: Blackwell, 2001

LEIKIN, M. et al. Listening with an Accent: Speech Perception in a Second Language by Late Bilinguals. J Psycholinguist Res, v. 38, p. 447-457, mar. 2009.

LI WEI. (org.). The Bilingualism Reader. London: Routledge, 2000.

MENDES, R. B. What is 'gay speech' in São Paulo, Brazil. In: SANTAEMILIA, J. et al. (org.). International Perspectives on Gender and Language. València: Universitat de València. 2007. 
MENDES, R. B. Percepção e Performances de Masculinidades: efeitos da concordância nominal de número e da pronúncia de /e/ nasal. 2018. Tese (Livre Docência) Faculdade de Filosofia, Letras e Ciências Humanas, Universidade de São Paulo, São Paulo, 2018.

MILROY, L.; MUYSKEN, P. (org.). One Speaker, Two Languages: cross-disciplinary perspectives on code-switching. Cambridge: Cambridge University Press, 1995.

OUSHIRO, L. Introdução à Estatística para Linguistas. 2017. Disponível em: http://rpubs. com/oushiro/iel. Acesso em: 26 nov. 2018.

OUSHIRO, L. Identidade na pluralidade: avaliação, produção e percepção linguística na cidade de São Paulo. 2015. Tese (Doutorado em Semiótica e Linguística Geral) Faculdade de Filosofia, Letras e Ciências Humanas, Universidade de São Paulo, São Paulo, 2015.

PODESVA, R. et al. Constraints on the social meaning of released /t/: A production and perception study of U.S. politicians. Language Variation and Change, Cambridge: Cambridge University Press, v. 27, p. 59-87, mar. 2015.

POPLACK, S. Sometimes I'll start a sentence in Spanish y termino en español: toward a typology of code-switching. Linguistics, v. 18, p. 581-618, jan. 1980.

PORTO, R. S. Code-switching: perspectivas multidisciplinares. 2006. Dissertação (Mestrado em Letras) - Pontifícia Universidade Católica do Rio de Janeiro, Rio de Janeiro, 2006.

R CORE TEAM (2019). R: A language and environment for statistical computing. $R$ Foundation for Statistical Computing, Vienna, Austria, 2013. Disponível em http:// www.R-project.org/. Acesso em: 31 jul. 2019.

THOMASON, S. G. Language Contact: an introduction. Washington, D.C.: Georgetown University Press, 2001. 


\section{ANEXOS}

\section{Voces X}

Este cuestionario se utilizará para fines de investigación académica. Se conservará toda la información personal.

*Obrigatório

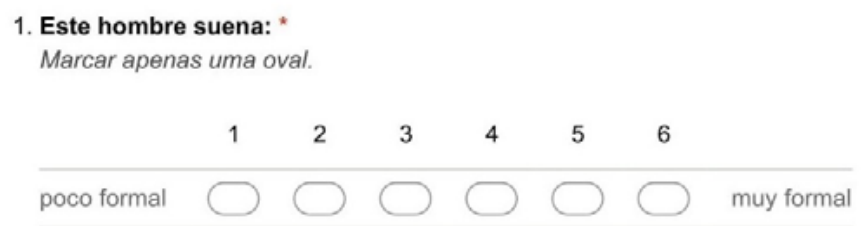

2. *

Marcar apenas uma oval.

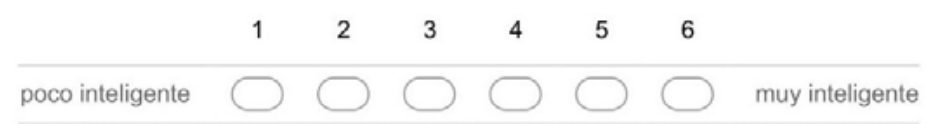

3. *

Marcar apenas uma oval.

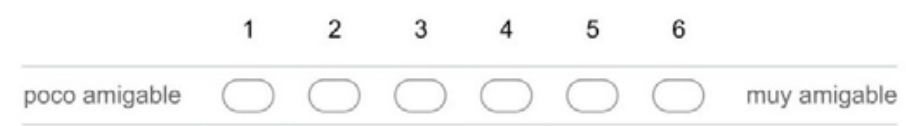

4. *

Marcar apenas uma oval.

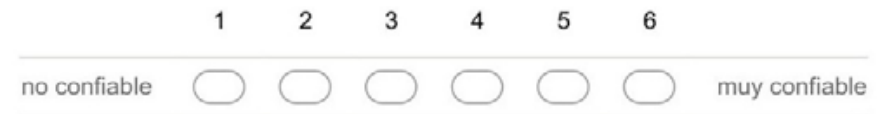

5. *

Marcar apenas uma oval.

$\begin{array}{lllllll}1 & 2 & 3 & 4 & 5 & 6 & \\ \text { menos hispánico } \square & \square & \square & \square & \square & \square & \square\end{array}$

6. *

Marcar apenas uma oval.

$\begin{array}{lllllll}1 & 2 & 3 & 4 & 5 & 6 & \\ \text { muy timido } \square & \square & \square & \square & \square & \square \text { muy extrovetido }\end{array}$


7. De lo que ha escuchado, este hombre parece ser: (elija todas las opciones que se adecuen) *

Marque todas que se aplicam.
divertido
religioso
relajado
inculto
habilidoso
trabajador
nacionalista
perezoso
gay
ingenioso
molesto
solitario
experto
hétero
brasileño

\section{Conteste sobre usted:}

Por favor, rellene los siguientes campos con sus datos.

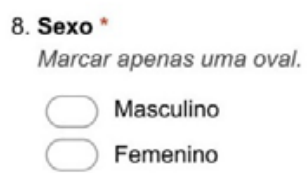

9. Escolaridad *

Marcar apenas uma oval.

Nivel Básico

Nivel Secundario

Nivel Superior

10. Edad *

11. Ocupación *

12. Ciudad donde vive *

13. Local de nacimiento *

14. Hace cuánto tempo vive en São Paulo? *

\section{Powered by}

Google Forms 